\title{
Hubungan Antara Harga Diri Dengan Perilaku Impulsive Buying Pada Remaja Penggemar K-Pop
}

\author{
Nafeesa $^{1}$, Eryanti Novita ${ }^{2}$ \\ ${ }^{1,2}$ Fakultas Psikologi, Universitas Medan Area \\ e-mail: nafeesampsi@gmail.com
}

Cara Sitasi: Nafeesa, Eryanti N (2021) Hubungan Antara Harga Diri Dengan Perilaku Impulsive Buying

Pada Remaja Penggemar K-Pop, 2021 21(2), 79 - 86 Retrieved from https://doi.org/10.31294/jc.v19i2

\begin{abstract}
KPop is currently a trend for some teenagers. Most of these teenage Kpop fans feel that being a fan also has to collect various kinds of goods or what is commonly known as merchandise related to their idols. They assume that buying these items will make them true fans no matter what the price. They are willing to spend up to millions of rupiah to get their idol's original products such as albums, clothes, bags, pants, hats, bracelets and so on. Furthermore, this study will analyze the problem of high idol impulsive buying behavior in the adolescent community and determine the relationship between self-esteem and impulsive buying behavior in adolescents. This study will specifically examine whether there is a relationship between self-esteem and impulsive buying behavior in adolescents. This research will use Coopersmith's theory of self-esteem and Rook and Fisher's theory of impulsive buying, which is then examined in terms of its aspects and characteristics.
\end{abstract}

Keywords : Teens, KPop Fans, Impulsive Buying, Self-Esteem.

\section{PENDAHULUAN}

Saat ini kaum remaja sangat mengidolakan seseorang yang bisa dijadikan panutan. Sejak tahun 2009 hingga sekarang korean wave atau demam korea tidak pernah surut dari penggemar yang fanatik. Selain tampang, musik, dan teknologi semakin canggih yang dapat memperlihatkan keseharian idola mereka, membuat remaja saat ini semakin menggilai dan tidak pernah melepaskan pandangannya barang sedikitpun dari Kpop (Korean pop). Mereka bisa melihat betapa idola mereka berkerja keras dan sangat disiplin dalam kehidupan selebritisnya. Itulah yang membuat remaja maupun dewasa jaman sekarang menyukainya dan banyak menghabiskan uang dan tenaga hanya untuk melihat idola mereka. Baik melalui media seperti youtube, instagram, twitter maupun melihat langsung dengan datang ke konsernya dan lain-lain.

Ketika membicarakan Korean pop maka para penggemar tidak luput dari merchandise yang asli Korea maupun buatan Indonesia asalkan barang tersebut menyangkut idola mereka. Mulai dari barang yang penting sampai yang tidak penting dan membawa kesenangan bagi mereka sehari-hari.

Fenomena menggemari Korean pop semakin meningkat dan tidak pernah surut selama 10 tahun terakhir dan semakin meluasnya teknologi, semua orang semakin mudah untuk berbelanja, baik langsung ke toko maupun online untuk membeli barnag-barang menyakut idola mereka yang mereka sukai tanpa berfikir panjang. Remaja ingin memuaskan keinginan tersiernya dengan membeli barang-barang idola mereka tanpa memikirkan dampak kedepannya. Banyaknya boyband membuat semakin banyak juga komunitas yang dibangun disemua negara dan Korea pun menargetkan Indonesia menjadi salah satu penyebaran budayanya. Musik, film, pakaian, dan segala hal lain berbau Korea mendapat sambutan yang begitu positif dari masyarakat Indonesia, terutama remaja. Banyak dari para remaja yang rela mengorbankan waktu hingga biaya agar mampu bertemu dengan idolanya.

Di Medan sejak tahun 2009 sudah memiliki komunitas-komunitas tertentu untuk saling berkumpul antar sesama penggemar boyband / girlband yang sama. Mereka berkumpul dan saling berbagi pengalaman juga tak luput untuk membeli barang-barang yang disediakan dikomunitas tersebut ketika komunitas tersebut menyelenggarakan suatu acara. Kemudian komunitas juga menggalang dana untuk beberapa kegiatan perlindungan alam seperti menggalang dana untuk pelestarian harimau di Sumatera \& Jawa karena beberapa boyband korea tersebut dilambangkan seperti harimau dan sebagainya. Sangat banyak remaja sekarang, walaupun mereka belum menghasilkan uang sendiri namun pengeluaran mereka terhadap barang KPop (Korean pop) lebih banyak daripada yang sudah kerja dan menghasilkan uang sekalipun.

Maka penelitian ini juga dilakukan dengan melihat jumlah penghasilan orang tua mereka. Impulse buying merupakan fenomena yang terjadi dalam kehidupan sehari-hari dilakukan tanpa sadar baik oleh laki-laki maupun perempuan. Menurut 
Winawan dan Yasa (2014) laki-laki dan perempuan memiliki kecenderungan yang sama dalam melakukan impulsive buying. Banyak mall maupun online shop menjual barang-barang kpop (Korean Pop) dan sangat laku karena remaja maupun dewasa banyak meminati barang-barang yang berkaitan dengan idola mereka.

Tulisan ini melihat hubungan harga diri dengan impulse buying pada remaja di sebuah cafe yang terletak di Jalan Wahid Hasyim no. 54 yang merupakan basecamp ataupun tempat seringnya terlaksana acara perkumpulan penggemar korea tersebut. Selain melakukan perkumpulan dan membuat acara rutin seperti merayakan ulang tahun artisnya, mereka juga menjual accessories korea seperti gantungan kunci, pelindung hp (case), tas, topi, dan barang-barang lainnya yang sangat mahal apabila produk tersebut asli atau original dengan kisaran harga 100-900rb sesuai dengan item yang ingin mereka beli. Mereka juga menjual poster dan photocard kecil yang juga tak kalah mahal dengan disertai tanda tangan idola mereka. Melalui kajian latar belakang masalah di atas, terdapat beberapa permasalahan yang dapat diidentifikasi. Adapun beberapa permasalahan yang diidentifikasi yaitu tingginya perilaku impulsive buying terhadap idola pada komunitas remaja, terdapat individu yang memiliki harga diri yang rendah terhadap nya. Dan dari beberapa indikasi yang dipaparkan diatas, penulis tertarik untuk mengetahui hubungan antara harga diri dengan perilaku impulsive buying pada remaja.

\section{TINJAUAN PUSTAKA}

Menurut Santrock (2007) remaja merupakan suatu periode dimana kematangan kerangka dan seksual terjadi secara pesat terutama pada awal masa remaja. Masa remaja terjadi secara berangsur-angsur tidak dapat ditentukan secara tepat kapan permulaan dan akhirnya, tidak ada tanda tunggal yang menandai. Bagi anak laki-laki ditandai dengan tumbuhnya kumis dan pada anak perempuan ditandai dengan melebarnya pinggul. Hal ini dikarenakan pada masa ini hormon-hormon tertentu meningkat secara drastis. Pada anak laki-laki hormon tertosteron yaitu suatu hormon yang berkait dengan perkembangan alat kelamin, pertumbuhan tinggi dan perubahan suara.

Sedangkan pada anak perempuan hormon estradiol yaitu suatu hormon yang berkaitan dengan perkembangan buah dada, rahim, dan kerangka pada anak perempuan. Remaja juga diartikan sebagai masa perkembangan transisi emosional. Walaupun situasi budaya dan sejarah membatasi kemampuan untuk menentukan rentang usia remaja, di Amerika dan banyak budaya lain sekarang ini masa remaja dimulai kira-kira 10 sampai 13 tahun dan berakhir antara 1821 tahun. Menurut Zulkifli (2005) pada masa ini mereka mengalami banyak perubahan pada psikis dan fisiknya. Mereka penuh mengalami gejolak emosi dan tekanan jiwa sehingga mudah menyimpang dari aturan dan norma-norma sosial yang berlaku di kalangan masyarakat. Berdasarkan beberapa teori diatas dapat disimpulkan bahwa remaja sebetulnya tidak mempunyai tempat yang jelas. Remaja tidak termasuk golongan anak, tetapi ia tidak pula termasuk golongan orang dewasa atau golongan tua, posisinya ada diantara anak dan orang dewasa. Remaja masih belum mampu untuk menguasai fungsi-fungsi fisik maupun psikisnya. Remaja awal berusia 13-16 tahun dan remaja akhir berusia 17-21 tahun.

\section{Impulsive Buying}

Menurut Rook (dalam Henrietta, 2012) perilaku impulsive buying merupakan perilaku pembelian yang terjadi ketika adanya dorongan secara tiba-tiba, sangat kuat, dan keinginan membeli sesuatu dengan segara. Keinginan membeli sesuatu dengan segera tersebut diikuti oleh adanya konflik emosional dan cenderung mengabaikan konsekuensi yang diperoleh. Dorongan yang melibatkan konflik emosional ini dapat disebut sebagai dorongan psikologis atau psychological impulse. Dengan kata lain impulsive buying adalah dorongan psikologis atau psychological impulse seseorang sebagai kekuatan, desakan yang tak tertahankan, serta munculnya kecenderungan secara tiba-tiba untuk melakukan sesuatu tanpa adanya pertimbangan sebelumnya.

Rook \& Fisher (dalam Sari, 2014) Individu dengan kecenderungan impulsive buying yang tinggi akan lebih mungkin untuk terus terpengaruh stimulus pembelian yang spontan, walaupun mereka sudah merencanakan daftar barang yang akan dibeli sebelumnya, karena mereka mudah menerima ide pembelian yang tidak direncanakan secara tiba-tiba.

Berdasarkan definisi yang telah dijelaskan dapat disimpulkan bahwa impulsive buying adalah suatu pembelian yang dilakukan secara spontan dan secara tiba-tiba tanpa perencanaan sebelumnya dengan mengambil keputusan secara cepat. Biasanya pembelian secara spontan diikuti oleh aktivasi emosionalitas yang tinggi terhadap suatu produk tertentu. Hirschman dan Holbork (dalam Utami \& Sumaryono, 2008:46) bahwa pembelian impulsif ini kebanyakan disertai oleh faktor emosi karena aktivitas belanjanya bersifat bersifat hedonik. Pernyataan yang sama juga dikemukakan oleh Loudon \& Bitta (dalam Sari, 2014) bahwa pembelian impulsif atau pembelian tidak terencana adalah pembelian yang terjadi secara spontan dan tiba-tiba karena munculnya berdasarkan hasrat yang kuat untuk membeli dengan segera.

Faktor-faktor Impulsive buying 


\section{a. Faktor Eksternal}

Faktor eksternal adalah faktor yang berasal dari luar individu yang mempengaruhi impulsive buying, yaitu :

1. Promosi Pemasaran Produk, yaitu merujuk pada sebuah pemasaran atau stimulus yang dikendalikan promotor dalam upaya merayu konsumen agar timbul dorongan untuk melakukan pembelian (Dholakia, 2000). Pemasaran sangat berpengaruh pada proses pengambilan keputusan konsumen meliputi barang, yang dikenal sebagai produk, penempatan dan promosi, harga yang mempengaruhi proses pembelian konsumen pada berbagai tahap (Mariri, 2009).

2. Situasional dalam Toko, Menurut Hausman (2000) situasi toko dan pengaturan ritel mempengaruhi tanggapan individu di dalam toko dan keputusan toko di masa depan karena perubahan dan sifat adaptif dari harapan, preferensi, serta tingkah laku. Keputusan konsumen dipengaruhi oleh lingkungan toko yang menjual berbagai macam barang dagangan. Hal ini didukung oleh pernyataaan (Stern, dalam Hausman, 2000) bahwa pelayanan yang dilakukan sendiri dapat meningkatkan impulsive buying daripada pelayanan yang dilakukan oleh pegawai toko. Impulsive buying dapat terjadi karena pembeli dapat mengambil sendiri barang atau produk secara bebas dan cepat sesuai dengan yang diinginkan. Sedangkan jika dilayani oleh pegawai toko, pembeli tidak dapat leluasa memilih prduk yang diinginkan.

3. Store Display, Menurut (Karbasivar \& Yarahmadi, 2011) lingkungan yang ada di dalam toko adalah salah satu penentu yang sangat penting dari pembelian impulsif. Situasi ini terbentuk apabila letak ruang geografis didalam toko seperti musik, kebersihan toko, aroma, promosi di dalam toko, tampilan toko, harga, dan kepadatan toko. Store display yang menarik dapat meningkatkan daya tarik pembeli dan berpeluang untuk meningkatkan impulsive buying individu. Posisi rak, mempromosikan produk special atau new arrival (Hadjali, dkk., 2012), dan kemasan yang lebih menarik daripada produk-produk lainnya merupakan hal-hal yang dapat membuat store display lebih menarik (Stern, dalam Hausman 2000).

\section{b. Faktor Internal}

Faktor internal berasal dalam diri individu yang dapat mempengaruhi impulsive buying, yaitu :

1. Kecerdasan Emosi, dalam sebuah penelitian menghubungkan kecerdasan emosi dengan impulsive buying. Penelitian tersebut menyatakan bahwa orang yang memiliki kecerdasan emosi yang tinggi, impulsive buyingnya lebih rendah dibandingkan orang yang memiliki kecerdasan emosi yang rendah (Lin \& Chuang, 2005).

2. Usia, Penelitian yang dilakukan oleh (Lin \& Lin, 2005) menyatakan bahwa usia dapat mempengaruhi kecenderungan impulsive buying. Penelitian tersebut menggunakan subjek dengan rentang usia 15 - 19 tahun yang menunjukkan hasil bahwa remaja dengan usia 19 tahun memiliki skor tertinggi dalam impulsive buying, skor tertinggi kedua pada usia 15 tahun dan selanjutnya usia 17 tahun.

3. Gender, Gender merupakan faktor internal yang dapat mempengaruhi kecenderungan impulsive buying. Berdasarkan gendernya, perempuan cenderung memiliki tingkat pembelian yang tinggi dibandingkan pria. Hal tersebut dikarenakan kesenangan berbelanja dianggap perilaku yang wajar secara sosial dilakukan oleh perempuan dibandingkan laki-laki (Gasiorowska, 2011).

4. Mood, Mood juga dapat dikatakan sebagai faktor personal yang mempengaruhi impulsive buying. Individu yang memiliki moodnegatif cenderung trhindar dari perilaku impulsive buying. Sedangkan mood yang positif cenderung lebih mudah tertarik, bersemangat, loyal, merasa berharga, dan senang ketika melakukan impusie buying dibandingkan dengan individu yang memiliki mood negatif (Verplanken \& Herabadi, 2001).

5. Harga diri, Faktor lainya yang ada pada personal individu dalam impulsive buying yaitu harga diri. Penelitian yang dilakukan oleh (Hadjali, Salimi, dan Ardestani, 2012) menunjukkan bahwa semakin tinggi tingkat harga diri seseorang maka semakin rendah pembelian impulsfnya begitu juga sebaliknya jika harga diri individu rendah maka akan mudah melakukan pembelian yang impulsif.

6. Kontrol diri, Kontrol diri juga merupakan salah satu faktor personal yang dapat mempengaruhi impulsive buying. Seseorang yang mempunyai kontrol diri yang rendah, kurang mampu menahan setiap stimulus yang dapat mendorong pembelian impulsif, mudah terpengaruh dan tidak dapat mengendalikan diri dengan baik. Sedangkan orang yang memiliki kontrol diri yang tinggi akan membeli produk yang sudah dipertimbangkan dan sesuai dengan kebutuhanya (Baumeister, 2002).

Berdasarkan faktor-faktor impulsive buying diatas dapat disimpulkan bahwa faktor internal yang mempengaruhi adalah kecerdasan emosi 
sesorang, usia, gender, mood, harga diri dan kontrol dirinya.

\section{Harga Diri}

Menurut Coopersmith (dalam Susanto, 2018) harga diri merupakan evaluasi yang dibuat atas dasar kebiasaan dalam memandang diri sendiri, mengenai sikap penerimaan dan penolakan, dan merupakan besarnya kepercayaan terhadap kemampuan, keberartian, kesuksesan dan keberhargaan.

Coopersmith (dalam Ghufron \& Risnawita, 2016) menyatakan bahwa terdapat beberapa faktor yang mempengaruhi pembentukan harga diri seseorang, yaitu:

a. Keberartian Individu, berkaitan dengan seberapa besar individu percaya bahwa dirinya mampu, berarti dan berharga menurut standar serta nilai pribadi. Penghargaan dalam hal ini dimaksud dengan keberartian diri.

b. Keberhasilan Seseorang, berhubungan dengan kekuatan atau kemampuan individu dalam mempengaruhi dan mengendalikan diri sendiri maupun orang lain merupakan suatu keberhasilan yang berpengaruh terhadap pembentukan harga diri individu.

c. Kekuatan Individu, ini berkaitan dengan aturan, norma dan ketentuan yang ada dalam masyarakat. Semakin taat suatu individu terhadap berbagai hal yang telah ditetapkan dalam masyarakat, maka semakin besar kemampuannya untuk dapat dianggap sebagai panutan masyarakat. Dengan demikian, penerimaan masyarakat terhadap individu tersebut semakin tinggi dan hal ini mendorong harga diri yang tinggi.

d.Performansi Individu yang Sesuai dalam Mencapai Prestasi yang Diharapkan. Apabila individu mengalami kegagalan, maka harga dirinya akan rendah. Apabila performansi seseorang sesuai dengan tuntutan dan harapan, maka akan mendorong pembentukan harga diri yang tinggi.

Berdasarkan pernyataan Ghufron dan Risnawita (2016), harga diri seseorang terbentuk berdasarkan hasil interaksi individu dengan lingkungan dan atas penghargaan, penerimaan, dan pengertian orang lain akan dirinya. Beberapa faktor yang mempengaruhi harga diri, yaitu:

a. Jenis Kelamin. Menurut Ancok (dalam Ghufron \& Risnawita, 2016) wanita selalu merasa memiliki harga diri yang rendah dibandingkan pria, seperti merasa kurang mampu, kurang percaya diri, atau merasa dirinya harus dilindungi. Hal ini terjadi mungkin disebabkan oleh peran orang tua dan harapan masyarakat yang berbeda baik pada pria maupun wanita. Pendapat ini sejalan dengan penelitian Coopersmith yang membuktikan bahwa harga diri wanita lebih rendah dibandingkan pria.

b. Intelegensi. Menurut Coopersmith (dalam Ghufron \& Risnawita, 2016) individu dengan harga diri yang tinggi akan mencapai prestasi akademik yang tinggi dibandingkan individu dengan harga diri rendah. Individu dengan harga diri yang tinggi memiliki skor intelegensi yang lebih baik, selalu berusaha, dan memiliki taraf aspirasi yang lebih baik.

c. Kondisi Fisik. Coopersmith (dalam Ghufron \& Risnawita, 2016) menemukan bahwa terdapat hubungan yang konsisten antara daya tarik fisik dan tinggi badan dengan harga diri. Individu dengan kondisi fisik yang menarik cenderung memiliki harga diri yang lebih baik dibandingkan dengan yang kurang menarik.

d. Lingkungan Keluarga. Keluarga merupakan sumber pertama di mana seorang anak untuk pertama kalinya mengenal orangtua yang mendidik dan membesarkannya, serta merupakan dasar dalam melakukan sosialisasi dalam lingkungan yang lebih luas. Perilaku adil, memberikan kesempatan untuk aktif, dan mendidik dengan demokratis akan membuat anak memperoleh harga diri yang tinggi. Demikian dengan Savary (dalam Ghufron \& Risnawita, 2016) mengungkapkan bahwa keluarga memiliki peran dalam menentukan perkembangan harga diri anak. Orangtua yang sering menghukum dan melarang anak tanpa alasan akan dapat menyebabkan anak merasa tidak berharga.

e. Lingkungan Sosial. Menurut Klass dan Hodge (dalam Ghufron \& Risnawita, 2016), harga diri dibentuk ketika seseorang menyadari dirinya berharga atau tidak. Hal ini merupakan hasil dari proses lingkungan, penghargaan, penerimaan, dan perlakuan orang lain terhadapnya. Sedangkan menurut Coopersmith (dalam Ghufron \& Risnawita, 2016) beberapa perubahan dalam harga diri dapat dijelaskan melalui konsep kesuksesan, nilai, aspirasi, dan mekanisme pertahanan diri. Kesuksesan dapat timbul melalui pengalaman dalam lingkungan, kesuksesan dalam bidang tertentu, kompetisi, dan nilai kebaikan.

\section{METODOLOGI PENELITIAN}

Penelitian ini berjenis penelitian kuantitatif, dimana prosedur yang digunakan dalam penelitian ini adalah model korelasional. Maksud korelasi dari penelitian ini adalah untuk melihat hubungan antara variabel bebas (x) yaitu harga diri, dengan variabel terikat $(\mathrm{y})$ yaitu impulsive buying.

Harga diri atau self-esteem adalah penilaian atau evaluasi seseorang terhadap diri sendiri yang diperoleh berdasarkan hasil interaksi dengan orang 
lain, baik secara negatif maupun positif mengenai sejauh mana ia menganggap dirinya sebagai orang yang mampu, berkompeten, berarti dan berharga. Diukur berdasarkan aspek-aspek harga diri menurut Coopersmith (dalam Susanto, 2018). Yaitu kekuatan (power), keberartian (significance), kebajikan (virtue), dan kemampuan (competence).

Impulsive buying adalah suatu pembelian yang dilakukan secara spontan dan secara tiba-tiba tanpa perencanaan sebelumnya dengan mengambil keputusan secara cepat. Biasanya pembelian secara spontan diikuti oleh aktivasi emosionalitas yang tinggi terhadap suatu produk tertentu. Diukur berdasarkan ciri-ciri menurut Rook dan Fisher (dalam Kharis, 2011). Yaitu Spontan, Kegairahan dan stimulasi, Sinkronitas, Animasi produk, Pertentangan antara kontrol diri, Ketidakpedulian akan akibat.

Populasi dalam penelitian ini adalah 700 orang remaja di Medan. Sedangkan jumlah sampel sebanyak 45 orang remaja yang masuk kategori remaja awal sampai akhir berusia 13-20 tahun dan pernah melakukan pembelian secara spontan atas barang korea yang disukainya, kemudian dengan mengacu pada harga barang yang sering dibelinya.

Teknik pengambilan sampel dalam penelitian ini menggunakan teknik sampel purposive, karena sampelnya memiliki karakteristik yang sudah ditentukan dan diketahui berdasarkan ciri dan sifat populasinya (Winarsunu, 2010). Metode pengumpulan data yang digunakan dalam penelitian ini adalah metode skala. Menurut Noor (2016) skala adalah alat ukur yang digunakan untuk mengkuantifikasi informasi yang diberikan oleh suatu subyek dalam menjawab pertanyaan maupun pernyataan yang telah dirumuskan ke dalam suatu kuesioner. Dalam penelitian ini, terdapat dua skala ukur yaitu harga diri dan impulsive buying.

Skala ini disusun berdasarkan skala Likert dengan empat pilihan jawaban, yaitu Sangat Sesuai (SS), Sesuai (S), Tidak Sesuai (TS), dan Sangat Tidak Sesuai (STS). Pernyataan skala ini disusun dalam bentuk favorable dan unfavorable. Kriteria penilaian untuk pernyataan favorable berdasarkan skala Likert ini adalah nilai 1 untuk pilihan jawaban Sangat Tidak Sesuai (STS), nilai 2 untuk pilihan jawaban Tidak Sesuai (TS), nilai 3 untuk pilihan jawaban Sesuai (S) dan nilai 4 untuk pilihan jawaban Sangat Sesuai (SS). Sedangkan untuk pernyataan unfavorable, nilai 1 untuk pilihan jawaban Sangat Sesuai (SS), nilai 2 untuk pilihan jawaban Sesuai (S), nilai 3 untuk pilihan jawaban Tidak Sesuai (TS) dan nilai 4 untuk pilihan jawaban Sangat Tidak Sesuai (STS).

Validitas yang digunakan dalam penelitian ini adalah validitas isi, yaitu suatu alat pengukur yang ditentukan sejauh mana alat pengukur tersebut mewakili semua aspek yang dianggap sebagai aspek kerangka konsep (Sanusi, 2011) Untuk mengetahui validitas harga diri dengan impulsive buying menggunakan SPSS 16.0 for Windows. Teknik yang digunakan untuk menguji validitas alat ukur dalam penelitian ini dalah dengan analisis Product Moment dari Karl Pearson sebagai berikut:

$$
\mathrm{rxy}=\frac{\frac{\sum x y-\left\{\sum x\right\}\left\{\sum y\right\}}{N}}{\sqrt{\left\{\frac{\sum x^{2}-\left(\sum x\right)^{2}}{N}\right\}\left\{\frac{\sum y^{2}-\left(\sum y\right)^{2}}{N}\right\}}}
$$

Keterangan:

$\begin{array}{ll}\text { rxy } & \text { : Koefisien korelasi antara } \mathrm{x} \text { dan } \mathrm{y} \\ \mathrm{N} & \text { : Jumlah sampel } \\ \sum \mathrm{x} & \text { : Jumlah skor distribusi } \mathrm{x} \\ \sum_{\mathrm{y}} & \text { : Jumlah skor distribusi } \mathrm{y} \\ \sum_{\mathrm{X}}{ }^{2} & \text { : Jumlah kuadrat skor distribusi } \mathrm{x} \\ \sum_{\mathrm{y}} & \text { : Jumlah kuadrat skor distribusi } \mathrm{y} \\ \sum_{\mathrm{xy}} & \text { : Jumlah perkalian skor } \mathrm{x} \text { dan } \mathrm{y}\end{array}$

Uji reliabilitas yang digunakan dalam penelitian ini adalah uji reliabilitas Cronbach Alpha dengan rumus sebagai berikut :

$$
r_{11}=\frac{k}{k-1} \times\left\{1-\frac{\sum S_{i}}{S_{t}}\right\}
$$

Keterangan:

$$
\begin{array}{ll}
r_{11} & =\text { Nilai reliabilitas } \\
\sum \mathrm{Si} & =\text { Jumlah varians skor tiap-tiap item } \\
\mathrm{St} & =\text { Varians total } \\
\mathrm{k} & =\text { Jumlah item }
\end{array}
$$

Analisis korelasi yang digunakan adalah Pearson Product Moment dengan bantuan SPSS.

\section{HASIL DAN PEMBAHASAN}

Penelitian ini dilaksanakan pada anggota Kyeopta Kpopshop Medan yang memiliki anggota keseluruhan yang telah bergabung sejak awal berdiri sebanyak 194 anggota dan terdapat 73 anggota yang aktif saat ini. Kyeopta Kpop (Korean Pop) Shop adalah komunitas sesama penggemar korea yang berkumpul untuk saling mendukung idola korea dan juga untuk mengadakah kegiatan acara korea di kota Medan seperti bazar, perayaan ulang tahun idola, merayakan anniversary dan mereka juga menjual barang-barang idola korea tersebut.

Alat ukur yang digunakan dalam penelitian ini adalah

\begin{tabular}{|c|c|c|c|c|}
\hline \multirow[t]{2}{*}{ No } & \multirow[t]{2}{*}{ Aspek } & \multicolumn{2}{|c|}{ Nomor Aitem } & Jum \\
\hline & & Favorable & Unfavorable & lah \\
\hline
\end{tabular}
skala Kontrol Diri dan skala Impulsive Buying. Alat ukur yang dipersiapkan sebanyak 88 kuesioner.

Tabel 1.

Distribusi item Skala Kontrol Diri Setelah Uji Coba 


\begin{tabular}{|c|c|c|c|c|c|c|}
\hline & & Valid & $\begin{array}{c}\text { Gug } \\
\text { ur }\end{array}$ & $\begin{array}{c}\text { Vali } \\
\text { d }\end{array}$ & $\begin{array}{c}\text { Gugu } \\
\mathbf{r}\end{array}$ & \\
\hline 1 & $\begin{array}{c}\text { Behavior } \\
\text { al } \\
\text { Control }\end{array}$ & $\begin{array}{c}1,4,7 \\
10, \\
13,16 \\
, 18\end{array}$ & - & $\begin{array}{c}20,2 \\
3,26 \\
29, \\
32\end{array}$ & 35,38 & 14 \\
\hline 2 & $\begin{array}{c}\text { Cognitive } \\
\text { Control }\end{array}$ & $\begin{array}{c}2,5,8 . \\
11, \\
14,17 \\
, 19\end{array}$ & - & $\begin{array}{c}21,2 \\
4,27 \\
30,3 \\
6\end{array}$ & 33,39 & 14 \\
\hline 3 & $\begin{array}{l}\text { Decisiona } \\
\text { l Control }\end{array}$ & $\begin{array}{l}3,6,9 \\
12,15\end{array}$ & 38 & $\begin{array}{c}22,3 \\
1,34 \\
, 37\end{array}$ & 25,28 & 12 \\
\hline \multicolumn{6}{|c|}{ Total } & 40 \\
\hline
\end{tabular}

Berdasarkan uji validitas dan uji reliabilitas alat ukur diketahui skala Kontrol Diri terdapat 7 item yang gugur memiliki skor skor Corrected Item-Total Correlation (indeks daya beda $\mathrm{r}_{\mathrm{xy}}$ ) $<0,263$, yaitu item nomor 25,28,33,34,35,38,39. Dan 33 item lainnya valid memiliki skor Corrected Item-Total Correlation (indeks daya beda $\mathrm{r}_{\mathrm{xy}}$ ) $>0,312$, dengan skor bergerak dari rbt $=-0,042$ sampai $\mathrm{rbt}=0,725$, dengan skor reliabilitas (keandalan) CronbachAlpha 0,740 , yang berarti skala konsep diri tergolong reliabel.

Tabel 2.

Distribusi Penyebaran Butir-butir Pernyataan Impulsive Buying

\begin{tabular}{|c|c|c|c|c|c|}
\hline \multirow[t]{2}{*}{ Ciri-Ciri } & \multicolumn{2}{|c|}{ Favorable } & \multicolumn{2}{|c|}{ Unfavorable } & \multirow[t]{2}{*}{ Total } \\
\hline & Valid & $\begin{array}{c}\text { Gug } \\
\text { ur }\end{array}$ & Valid & $\begin{array}{l}\text { Gug } \\
\text { ur }\end{array}$ & \\
\hline Spontanitas & $1,5,9$ & - & 12,16 & - & 5 \\
\hline $\begin{array}{l}\text { Kekuatan, } \\
\text { kompulsi, } \\
\text { dan } \\
\text { intensitas }\end{array}$ & $\begin{array}{c}17,21 \\
23\end{array}$ & - & 20,22 & 28 & 6 \\
\hline $\begin{array}{l}\text { Kegairahan } \\
\text { dan } \\
\text { stimulasi }\end{array}$ & $\begin{array}{c}10,14 \\
19\end{array}$ & - & 26,32 & - & 5 \\
\hline Sinkronisasi & $\begin{array}{c}2,6 \\
15\end{array}$ & - & 29,36 & 33 & 6 \\
\hline $\begin{array}{l}\text { Animasi } \\
\text { produk }\end{array}$ & 5,13 & - & 37,41 & - & 4 \\
\hline Kepuasan & 11,21 & - & 24,30 & - & 4 \\
\hline $\begin{array}{c}\text { Pertentanga } \\
\text { n kontrol } \\
\text { diri dan } \\
\text { kesenangan }\end{array}$ & 3,7 & 25 & 31,38 & 34 & 6 \\
\hline $\begin{array}{c}\text { Ketidakped } \\
\text { ulian akan } \\
\text { akibat }\end{array}$ & 4,8 & 27 & 35,39 & - & 5 \\
\hline Total & 20 & 2 & 16 & 3 & 41 \\
\hline
\end{tabular}

Berdasarkan uji validitas dan uji reliabilitas alat ukur diketahui skala Impulsive Buying, terdapat 5 item yang gugur memiliki skor Corrected Item-Total Correlation (indeks daya beda $r_{\mathrm{xy}}$ ) $<0263$, yaitu item nomor $(25,27,28,33,34)$. Dan 36 item lainnya valid memiliki skor Corrected Item-Total Correlation (indeks daya beda $\left.r_{x y}\right)>0,263$, dengan skor bergerak dari $\mathrm{rbt}=0,025$ sampai $\mathrm{rbt}=0,738$ dengan skor reliabilitas (keandalan) CronbachAlpha 0,740, yang berarti skala kecendrungan gaya hidup hedonisme tergolong reliabel.

Berdasarkan analisis yang telah dilakukan, maka diketahui bahwa data penelitian alat ukur Kontrol Diri dan Impulsive Buying berdistribusi normal. Kriteria untuk menentukan normal atau tidaknya data, maka dapat dilihat pada nilai probabilitas (Sig), jika nilai Sig >0,05 maka data adalah berdistribusi normal dan sebaliknya apabila $\mathrm{p}<0,05$ sebarannya dinyatakan tidak normal. (Juliandi dkk, 2016). Berikut adalah hasil perhitungan uji normalitas sebaran tersebut yang dapat dilihat pada tabel 4.6 di bawah ini.

Tabel 3.

Hasil Uji Normalitas Tiap Variabel

\begin{tabular}{|c|l|l|l|l|c|}
\hline $\begin{array}{c}\text { Variabe } \\
1\end{array}$ & Mean & SD & K-S & P & $\begin{array}{c}\text { Keterang } \\
\text { an }\end{array}$ \\
\hline $\begin{array}{c}\text { Kontrol } \\
\text { Diri }\end{array}$ & 71.2 & 4,68 & $\begin{array}{l}0,33 \\
7\end{array}$ & $\begin{array}{l}0.09 \\
8\end{array}$ & Normal \\
\hline $\begin{array}{c}\text { Impulsi } \\
\text { ve } \\
\text { buying }\end{array}$ & 4 & 4 & 8 & 0 & \\
\hline
\end{tabular}

Ket :

Mean : Nilai rata-rata

SB : Simpangan Baku (Standart Deviasi)

K-S : Koefisien Kolmogorov-Smirnov

$\mathrm{P} \quad$ : Signifikansi

Hasil uji linearitas menunjukkan bahwa Kontrol Diri memiliki hubungan yang linear dengan Impulsive buying. Sebagai kriterianya, apabila p deviation form linierity beda $>0,05$ maka dinyatakan mempunyai derajat hubungan yang linier. Hasil uji linearitas hubungan dapat dilihat pada tabel 4.7 di bawah ini.

Tabel 4.

Hasil Uji Linearitas Hubungan 


\begin{tabular}{|c|c|c|c|}
\hline Korelasional & $\mathbf{F}$ & $\mathbf{P}$ & Keterangan \\
\hline $\mathbf{X}-\mathbf{Y}$ & $\mathbf{1 , 5 2 5}$ & $\mathbf{0 , 1 3 4}$ & Linear \\
\hline
\end{tabular}

Ket :

$\begin{array}{ll}\mathrm{X} & \text { : Kontrol Diri } \\ \mathrm{Y} & \text { : Impulsive Buying } \\ \mathrm{F} & \text { : Koefisien Linieritas } \\ \mathrm{P} & \text { : Signifikansi }\end{array}$

Berdasarkan output di atas diperoleh nilai Deviation from Linearity Sig. adalah 0,134 dimana lebih besar dari 0,05. Dengan demikian dapat disimpulkan bahwa ada hubungan linear secara signifikan antara Kontrol Diri dengan Impulsive Buying.

Kontrol diri merupakan salah satu aspek yang berkaitan dengan emosi individu. Kontrol diri menunjukkan bahwa individu mampu memandu, serta mengarahkan dan mengatur tindakan atau perilakunya dalam menghadapi stimulus atau rangsangan yang datang dari luar sehingga menghasilkan akibat yang sesuai dengan keinginannya atau individu terhindar dari akibat yang tidak diinginkannya. Hal ini sesuai dengan pendapat Larasati \& Budiani (2014) yang menyatakan bahwa kontrol diri sebagai suatu aktivitas pengendalian tingkah laku. Individu memiliki pertimbanganpertimbangan ketika berperilaku. Semakin tinggi kontrol diri individu, maka semakin tinggi pula pengendalian diri individu terhadap tingkah lakunya.

Hasil analisis Pearson's Product moment correlation pada penelitian ini menunjukkan bahwa terdapat hubungan negatif antara kontrol diri dengan impulsive buying pada remaja di Kyeopta Kpopshop Medan. Hal tersebut berarti bahwa semakin tinggi kontrol diri yang dimiliki oleh remaja di Kyeopta Kpopshop Medan maka semakin kecil kecenderungannya untuk melakukan impulsive buying. Demikian pula sebaliknya, semakin rendah kontrol diri remaja di Kyeopta Kpopshop Medan maka semakin besar kecenderungannya untuk melakukan Impulsive Buying.

Hasil analisis data di atas menjelaskan bahwa responden penelitian ini memiliki kontrol diri yang rendah dalam merespon stimulus. Stimulus yang dimaksud adalah produk-produk asal Korea yang seharusnya sangat menarik minat responden untuk membelinya, mengingat responden penelitian ini adalah anggota grup Kyeopta Kpopshop Medan dalam media sosial Line dan Whatsapp, yang artinya mereka tentu sangat menyukai gaya hidup orang Korea. Maka demikian, realita itu lantas membuat mereka memiliki sikap impulsive buying terhadap produk-produk yang berasal dari Korea. Anggota grup Kyeopta Kpopshop Medan tidak bisa menahan dan mengotrol tingkah lakunya sesuai dengan norma sosial, yakni tidak hanya membeli produk-produk Korea yang sesuai dengan kebutuhannya saja, tetapi memaksakan diri membeli produk-produk Korea atas dasar kesenangan belaka, dorongan dari dalam diri yang sangat kuat / keinginan yang tinggi untuk membeli maupun ikut-ikutan membeli karena temantemannya juga membelinya. Hal tersebut juga menjelaskan bahwa anggota grup Kyeopta Kpopshop Medan cenderung memaksakan diri membeli produkproduk Korea hanya atas dasar ambisi atau mengikuti trend saja, tidak membeli produk-produk Korea hanya yang benar-benar mereka butuhkan.

Hasil penelitian ini seperti diuraikan di atas sesuai dengan hasil penelitian terdahulu yang dilakukan oleh Chita, dkk. (2015) yang menyimpulkan kontrol diri berhubungan negatif terhadap impulsive buying. Remaja yang memiliki kontrol diri yang rendah sering kesulitan menentukan konsekuensi atas tindakan mereka, sedangkan remaja dengan kontrol diri tinggi sangat memperhatikan cara-cara yang tepat untuk berinteraksi dalam situasi yang bervariasi.

Demikian halnya hasil penelitian yang dilakukan Putri (2016) menyatakan bahwa terdapat hubungan negatif antara kontrol diri dengan impulsive buying. Hal tersebut berarti semakin tinggi kontrol diri maka semakin rendah impulsive buying. Begitu pula sebaliknya, semakin rendah kontrol diri maka semakin tinggi impulsive buying. Hasil penelitian ini juga mendukung hasil penelitian Roberts dan Manolis (2012) yang menyimpulkan bahwa kontrol diri memiliki hubungan yang negatif dengan impulsive buying. Semakin tinggi kemampuan kontrol diri seseorang maka semakin rendah impulsive buying.

Seseorang yang mempunyai kontrol diri yang rendah akan kurang mampu menahan setiap stimulus yang dapat mendorong impulsive buying, mudah terpengaruh dan tidak dapat mengendalikan diri dengan baik. Sedangkan orang yang memiliki kontrol diri yang tinggi akan membeli produk yang sudah dipertimbangkan dan sesuai dengan kebutuhannya.

Remaja sangat rentan terhadap kecenderungan sikap impulsive buying. Remaja diharapkan agar mampu mempertahankan kontrol dirinya sehingga bisa mengendalikan impulsive buyingnya. Sementara itu, bagi remaja dengan impulsive buying yang tinggi diharapkan mampu melatih dan meningkatkan kontrol dirinya agar dapat mengendalikan impulsive buying. Hal ini perlu dilakukan untuk melatih kontrol diri pada remaja dalam mengendalikan impulsive buyingnya.

\section{REFERENSI}

Anin F, Anastasia (2009). Hubungan self monitoring dengan impulsive buying terhadap produk fashion pada remaja. Jurnal Psikologi vol. 35, 181-193.

Bong, S. (2011). Pengaruh In-Store Stimuli Terhadap Impulsive buying Behavior Konsumen 
Hypermarket di Jakarta. Ultima Management Vol. 3 (1)

Ghufron, M.N dan Risnawati, R.S. (2010). Teoriteori Psikologi. Yogyakarta: ArRuzz Media.

Gulo, W. (2002). Metodologi Penelitian. Jakarta: Gramedia Widiasarana Indonesia.

Hendriyadi, Suryani. (2016). Metode Riset Kuantitatif: Teori dan Aplikasi pada Penelitian Bidang Manajemen dan Ekonomi Islam. Jakarta: Prenadamedia Group.

Henrietta P. D. A. D. S., M. A. (2012). Impulsive buying Pada Dewasa Awal di Yogyakarta. Jurnal Psikologi Universitas Sanata Dharma Yogyakarta. Vol 11(2).

Hurlock, E. B. (2000) Psikologi Perkembangan. Jakarta: Penerbit Erlangga.

Japrianto, E. \& Sugiharto, S. (2011). Pengaruh Shopping Life Style dan Fashion Involment Terhadap Impulsive buying Behavior Masyarakat High Income Surabaya. Jurnal Manajemen Pemasaran, Vol.6 (1).

Noor, S. (2011). Metodologi Penelitian: Skripsi, Tesis, Disertasi, dan Karya Ilmiah, Rawamangun, Jakarta: Kencana.

Santrock, John. W. (2007). Psikologi Pendidikan. Jakarta: Salemba Humanika.

Saputra, Tri Reza. (2017). Hubungan Antara Gaya Hidup Hedonisme Dengan Kecenderungan Impulsive buying Terhadap Trend Fashion Pada Remaja Kota , Jurnal Psikologi.

Sari, A.E. (2014). Analisis Faktor yang Mempengaruhi Pembelian Spontan. Jurnal sains pemasaran Indonesia, Volume 13(1), 55 -
73.

Sanusi, A. (2011). Metodologi Penelitian Bisnis. Jakarta: Salemba Empat.

Susanto, A. (2018). Bimbingan dan Konseling di Sekolah: Konsep, Teori, dan Aplikasinya. Jakarta: Kencana.

Sugiyono. (2017). Metode Penelitian Kuantitatif, Kualitatif, dan R\&D. Bandung: Alfabeta

Sumarwan, U., A. Jauzi, A. Mulyana, B. N. Karno, P.K. Mawardi, dan W. Nugroho. (2011). Riset Pemasaran dan Konsumen; Panduan Riset DAN Kajian: Kepuasan, Perilaku Pembelian, Gaya Hidup, Loyalitas, dan Persepsi Resiko. Kampus IPB Taman Kencana. PT. Penerbit IPB Pers. Bogor

Utami, A.F dan Sumaryono. (2008). Pembelian Impulsif Ditinjau Dari Kontrol Diri Dan Jenis Kelamin Pada Remaja. Jurnal Psikologi Proyeksi (Online), 3, (1).

Widyarini, N. (2009). Kunci Pengembangan Diri. Jakarta: PT. Elex Media Komputindo.

Zulkifli L (2005). Psikologi Perkembangan. Bandung: PT Remaja Rosdakarya

\section{PROFIL PENULIS}

Penulis (1), merupakan dosen Fakultas Psikologi Universitas Medan Area.

Penulis (2), merupakan dosen Fakultas Psikologi Universitas Medan Area. 